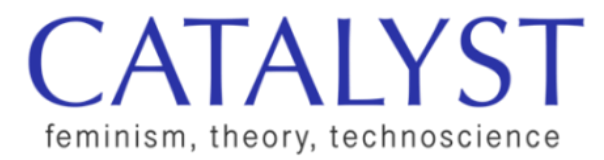

\title{
Book Review | Secret Cures of Slaves: People, Plants, and Medicine in the Eighteenth-Century Atlantic World, by Londa Schiebinger (Stanford University Press, 2017)
}

\author{
Élodie Edwards-Grossi \\ Université Toulouse-Jean Jaurès \\ elodie.edwards-grossi@univ-tlse2.fr
}

In Secret Cures of Slaves, Londa Schiebinger explores the history of experimentation on human bodies by European physicians in the West Indies and the cures and techniques of self-care that African and Amerindian healers developed throughout the eighteenth century in the French and British West Indies. Many recent history books have focused on race and medicine by unveiling the brutal exploitation of Black bodies by white physicians in the United States in the slavery era-looking at the history of white physicians theorizing and experimenting on Black bodies (Willoughby 2018; Kenny 2013); the founding of gynaecology (Cooper Owens 2017); illness, care, and the history of the Freedmen's Bureau during the Civil War and Reconstruction (Downs 2012), all of which follow in the wake of Todd Savitt's (1982) ground-breaking work on Black health in the antebellum era. Fewer books, however, have tackled the transnational history of burgeoning medical techniques developed both by African and Amerindian naturalists and European physicians in the Atlantic World.

Londa Schiebinger's book follows on from Sharla Fett's (2002) work, which shows how enslaved men and women drew on African precedents to develop new techniques of healing that were in opposition to slaveholders' productivity concerns. While Fett's book documents how slave communities, through their own health practices, built a strong resilience network against techniques of domination and abuse that were systematically deployed by white slaveholders and overseers on the plantations, Schiebinger provides further details on the

Edwards-Grossi, Élodie. 2021. Review of Secret Cures of Slaves: People, Plants, and Medicine in the Eighteenth-Century Atlantic World, by Londa Schiebinger (Stanford University Press, 2017).

Catalyst: Feminism, Theory, Technoscience 7 (2): 1-5.

http://www.catalystjournal.org|ISSN: 2380-3312

(C) Élodie Edwards-Grossi, 2021 | Licensed to the Catalyst Project under a Creative Commons Attribution Non-Commercial No Derivatives license 
human experimentations carried out by white physicians on Black bodies. She also elaborates on the question of the "interchangeability of bodies" (6), a notion that complicates the history of early conceptions of "race" in the British and French West Indies that tended to treat the bodies of the poor, displaced, and enslaved as representative of human bodies more generally (Schiebinger 2013).

Schiebinger's book kicks off with an introduction that presents the existing literature on colonial medicine, science, and race in the eighteenth century, after which the book is divided into five chapters, each tackling a specific theme. Chapter 1 focuses on the circulation of knowledge between European medical centers and Europe's far-flung colonies, such as Jamaica and Saint-Domingue. Schiebinger explores how European physicians Jean-Barthélémy Dazille in SaintDomingue, Bertrand Bajon in Saint-Domingue and Cayenne, and John Williamson in Jamaica used "experimental empiricism" (using Black corpses for dissection, or experimenting on slaves when visiting plantations) to gain "much knowledge of medical art" (24) in hot climates. However, the author shows that these colonial experimentalists not only focused on reconfiguring European-developed techniques for use in the colonies, they also used Amerindian and African cures "because of their effectiveness" (24). Slave owners paid these doctors in the West Indies to bring their expertise on health and bodies to increase the productivity on the plantation and to "submit [the slaves] to hard work without revolt" (28). For example, these physicians cautioned planters to choose their slaves with care and sought to identify distinct pathologies in slaves from various regions in Africa. At the same time, European British and French physicians, informed by debates over skin color and climate, tried to measure whether successful acclimatization of African slaves to tropical territories such as Saint-Domingue or Jamaica could be systematized to further increase labor production (38).

Chapter 2 reveals how European physicians such as Alexander J. Alexander "evaluated what they deemed slave cures" (45) before putting them to use. African medical regimes were often elaborated by slaves in deep connection with the Africanization of other cultural and religious practices on the plantations, as shown by historians Judith Carney and Richard Rosomoff (2009), as well as the growing of African subsistence crops (45). Perhaps one of Schiebinger's most interesting contributions to the literature is her demonstration of how "the fusion of African and Amerindian knowledge systems" (46) participated in the creation of new plant-based cures on the plantations. Slaves, for example, sometimes used tobacco leaves as a remedy against persistent headaches, tobacco being "indigenous to the Americas" (47).

In Chapter 3, Schiebinger returns to the question of how European doctors conducted human experiments on enslaved bodies and whether they would take into account ethical considerations when practicing medicine. Clinical wards in Europe served as medical laboratories in urban contexts in the eighteenth 
century, and later transferred some of their techniques to colonial soils to serve new purposes (66). As Schiebinger points out, there were no "ethical safety brakes other than personal conscience" (67) to regulate experimentation on human bodies. An ethical framework would only become institutionalized in the twentieth century after the 1979 Belmont Report was issued in the United States, largely in response to the Tuskegee Syphilis Experiments and the atrocities perpetrated by Nazi medical authorities during the Second World War (65). In the eighteenth century, as the author demonstrates, a principle of "public utility" (70)-devalued members of society were revalued by lending their bodies to medicine-prevailed over the necessities of coming to the assistance of vulnerable populations such as slaves, which partly explains why physicians in the West Indies sought to perform experiments on the bodies of slaves (74).

Chapter 4 further explores the topic of human experiments, by focusing on "exploitative experiments" (91) and physician John Quier's smallpox experiments in the rural highlands of Jamaica. The author shows how Quier "freely experimented with smallpox inoculation in a population of 850 slaves under his care" (92), which resulted in the epidemic of 1768 that swept across the island. Quier's experiments demonstrate that colonial physicians often selected racialized subjects for experiments and that medical practices were frowned upon in Europe. This chapter, therefore, further highlights the differential ethical protocols that white physicians followed in relation to racialized subjects who they considered "less human" than their European counterparts.

The last chapter of the book, "The Colonial Crucible," delves further into the colonial context by unveiling how British and French colonial administrations regulated moral conducts in the colonies by relying on the expertise of West Indian colonial doctors. Colonial physicians carried out experimentations on slave bodies as a way to contain slave riots (117), which shows how medical practices served the colonial order. Doctors, therefore, played upon the fear and vulnerability of slave populations to suppress political uprisings, while some medical doctors, such as John Quier and William Wright, were themselves part of the colonial elite in Jamaica as plantation owners (117).

The book stimulates a much-needed conversation about transnational dynamics and medicine in the eighteenth century, joining Pablo Gómez's (2014) and Rana Hogarth's works (2017) on the circulation of medical theories and practices in the Atlantic World. Schiebinger focuses not only on US slavery but on the Atlantic World and therefore tackles the circulation of medical theories and techniques between French and British physicians in Europe, European colonial physicians in the colonies, and African and Amerindian healers in the West Indies, within what she names "the Atlantic World medical complex" (3). 
Perhaps one shortcoming of the book is the fact that the author glides over the power relations that existed between these physicians; they held very different statuses within Europe and the Americas. A closer look at power dynamics and at scientific authority would have produced a more nuanced picture of the circulation of knowledge within these slavery societies. Furthermore, a more detailed look at gendered dynamics, only rapidly mentioned in Chapter 2 when dealing with Madame Rousseau (48), would have instructively complicated the moral economy of knowledge circulation and knowledge production on the plantations in the Atlantic World. Schiebinger's work, however, provides historical insights that can be read in conversation with scholarship by Cooper Owens (2017) and Fett (2002), who focus more on the important role enslaved women played in relation to plantation health culture; they often secretly made plant-based medicines, cared for the sick, and served as midwives in both Black and white households, and therefore disputed the authority of white doctors on the plantations. Finally, while the book deals overwhelmingly and convincingly with the topics of human experimentation and ethics in the eighteenth century, the book title refers to slave cures, and these are only dealt with in Chapter 2. Although "secrecy" appears in the book's title, Schiebinger does not elaborate upon this notion in relation to slaves' cures-a peculiar omission given that secrecy is a key element of power dynamics in knowledge production.

Nonetheless, Schiebinger delivers a stimulating book that obliges us to reconsider the dynamics of plantation healing and the production of knowledge in a multisituational network of relations. Consequently, the book also opens new pathways for contributions and reflections on the history of physicians in the West Indies in relation to human experimentation and Indigenous peoples' knowledge, and provides a model for conducting similar research on practices in the nineteenth and twentieth centuries.

\section{References}

Carney, Judith, and Richard Nicholas Rosomoff. 2009. In the Shadow of Slavery: Africa's Botanical Legacy in the Atlantic World. Berkeley: University of California Press.

Cooper Owens, Deirdre. 2017. Medical Bondage: Race, Gender, and the Origins of American Gynecology. Athens: University of Georgia Press.

Downs, Jim. 2012. Sick from Freedom: African-American Illness and Suffering during the Civil War and Reconstruction. Oxford, UK: Oxford University Press.

Fett, Sharla. 2002. Working Cures: Healing, Health, and Power on Southern Slave Plantations. Chapel Hill: University of North Carolina Press.

Gómez, Pablo. 2014. "Incommensurable Epistemologies? The Atlantic Geography of Healing in the Early Modern Black Spanish Caribbean." Small Axe: A Caribbean Journal of Criticism 44: 95-107. https://doi.org/10.1215/07990537-2739875. 
Hogarth, Rana A. 2017. Medicalizing Blackness: Making Racial Difference in the Atlantic World, 1780-1840. Chapel Hill: University of North Carolina Press.

Kenny, Stephen C. 2013. "The Development of Medical Museums in the Antebellum American South: Slave Bodies in Networks of Anatomical Exchange." Bulletin of the History of Medicine 87 (1): 32-62. https://www.jstor.org/stable/26296837.

Savitt, Todd L. 1982. "The Use of Blacks for Medical Experimentation and Demonstration in the Old South." Journal of Southern History 48 (3): 331-48. https://doi.org/10.2307/2207450.

Schiebinger, Londa. 2013. "Medical Experimentation and Race in the EighteenthCentury Atlantic World." Social History of Medicine 26 (3): 364-82. https://doi.org/10.1093/shm/hkto11.

Willoughby, Christopher. 2018. "Running Away from Drapetomania: Samuel Cartwright, Medicine, and Race in the Antebellum South." Journal of Southern History 84 (3): 579-614. https://doi.org/ 10.1353/soh.2018.0164.

\section{Author Bio}

Élodie Edwards-Grossi is an associate professor at Université Toulouse-Jean Jaurès (France). Her work explores social history of racialized psychiatry in the United States and the medicalization of the Black body from the nineteenth century until the contemporary era. Her forthcoming book is tentatively titled Mad with Freedom: The Political Economy of Blackness, Insanity and Civil Rights in the US South, 1840-1920 (under contract with LSU Press). 